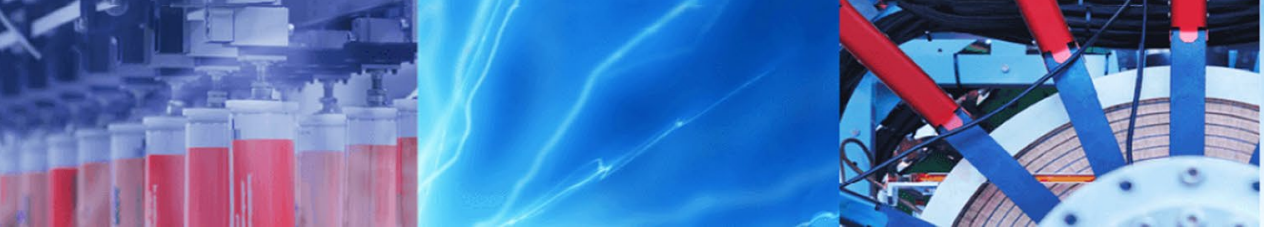

Research Article

\title{
Exposure levels of radiofrequency magnetic fields and static magnetic fields in 1.5 and 3.0 T MRI units
}

\author{
P. Rathebe ${ }^{1}$ (D) C. Weyers ${ }^{2} \cdot$ F. Raphela ${ }^{3}$
}

Received: 31 August 2020 / Accepted: 7 January 2021 / Published online: 19 January 2021

(C) The Author(s) 2021 OPEN

\begin{abstract}
Magnetic resonance imaging (MRI) staff is exposed to a complex mixture of electromagnetic fields from MRI units. Exposure to these fields results in the development of transient exposure-related symptoms. This study aimed to investigate the exposure levels of radiofrequency (RF) magnetic fields and static magnetic fields (SMFs) from 1.5 and 3.0 T MRI scanners in two public hospitals in the Mangaung Metropolitan region, South Africa. The exposure levels of SMFs and RF magnetic fields were measured using the THM1176 3-Axis hall magnetometer and TM-196 3 Axis RF field strength meter, respectively. Measurements were collected at a distance of $1 \mathrm{~m}(\mathrm{~m})$ and $2 \mathrm{~m}$ from the gantry for SMFs when the brain, cervical spine and extremities were scanned. Measurements for RF magnetic fields were collected at a distance of $1 \mathrm{~m}$ with an average scan duration of six minutes. Friedman's test was used to compared exposure mean values from two 1.5 T scanners, and Wilcoxon test with Bonferroni adjustment was used to identify where the difference between exist. The Shapiro-Wilk test was also used to test for normality between exposure levels in 1.5 and $3.0 \mathrm{~T}$ scanners. The measured peak values for SMFs from the 3.0 T scanner at hospital A were 1300 milliTesla (mT) and $726 \mathrm{mT}$ from $1.5 \mathrm{~T}$ scanner in hospital B. The difference in terms of SMFs exposure levels was observed between two $1.5 \mathrm{~T}$ scanners at a distance of $2 \mathrm{~m}$. The difference between $1.5 \mathrm{~T}$ scanners at $1 \mathrm{~m}$ was also observed during repeated measurements when brain, cervical spine and extremities scans were performed. Scanners' configurations, magnet type, clinical setting and location were identified as factors that could influence different propagation of SMFs between scanners of the same nominal $B_{0}$. The RF pulse design, sequence setting flip-angle and scans performed influenced the measured RF magnetic fields. Three scanners were complaint with occupational exposure guidelines stipulated by the ICNIRP; however, peak levels that exist at $1 \mathrm{~m}$ could be managed through adoption of occupational health and safety programs.
\end{abstract}

Keywords Static magnetic fields · Radio frequency fields · Occupational exposure $\cdot$ MRI scanners · Exposure levels

\section{Introduction}

The World Health Organisation (WHO) has classified both magnetic fields [1] and radiofrequency (RF) fields [2] as a possible carcinogenic to humans, "group 2B." Magnetic resonance imaging (MRI) has a complex mixture of electromagnetic fields (EMFs), ranging from static, low-frequency, and RF magnetic fields [3]. The MRI static magnetic fields
(SMFs) range from 0.5 to $3 \mathrm{~T}(T)$ for clinical examinations, and, in addition, the magnitude of RF fields $(\mu \mathrm{T})$ produced gives rise to specific absorption rates (SAR) [3], leading to increased tissue temperature and possible thermal damage [4], [5]. Transient effects resulting from exposure to MR-related EMFs have been well studied through health risk assessments in American and European countries [6-8]; however, current exposure scenarios in South

$\triangle$ P. Rathebe, prathebe@uj.ac.za | ${ }^{1}$ Department of Environmental Health, University of Johannesburg, Doornfontein Campus, Johannesburg, South Africa. ${ }^{2}$ Department of Life Sciences, Central University of Technology, Bloemfontein, Free State, South Africa. ${ }^{3}$ Department of Clinical Sciences, Central University of Technology, Bloemfontein, Free State, South Africa. 
African public healthcare sectors are not yet known (Rathebe [9]; Rathebe [10]). In exposure assessment studies conducted by Bongers et al. [6] and Huss et al. [8], an association was found between occupational exposure to SMFs and increased risks of accidents leading to occupational injuries. Health risk assessments performed by Wilén and de Vocht [11], Zanotti et al. [12] and Schaap et al. [13] suggest that exposure to MRI-SMFs is associated with unpleasant symptoms such as vertigo/dizziness, nausea, unusual drowsiness, sleep disorders, severe headaches, and concentration problems. Similarly, SMFs-exposure effects were also reported by Schaap et al. [14] and De Vocht et al. [15]. It should be noted that performing personal exposure measurements during the execution of a magnetic resonance (MR) exam involves considering exposure conditions that require the presence of an operator in the MR room during the exam in order to assess the entire exposure scenario. The MR operator may only be present in the MR scanner room during interventional procedures or when assisting patients with severe medical conditions. According to Karpowicz et al. [16], Gourzoulidis et al. [17], Frankel et al. [3], and Rathebe [9], exposure to RF fields is associated with thermal effects and excitation of electrosensitive tissues, which could lead to thermoregulatory failure.

The present guidelines focus on limiting occupational exposure to SMFs (ICNIRP [18]), high RF EMFs (ICNIRP [19]) and time-varying magnetic fields (ICNIRP [20]) that produces induced health outcomes as a result of movement of workers in the MRI (ICNIRP [20]; [21]. According to SCENIHR [22] and Frankel et al. [3], little attention has been given to cases where there is exposure to different MRI-related EMFs at the same time. In this study, RF magnetic fields and SMFs were quantified from 1.5 and 3.0 T MRI scanners to present an exposure scenario that could lead to induced thermal effects and SMF-related health outcomes. In 2017, Andreuccetti et al. investigated the exposure levels of SMFs near 1.5, 3.0 and 7T MRI scanners. The exposure data in 1.5 and 3.0 T were compliant with 2013/35/EU Directive exposure limit values for static fields and ICNIRP-[20] basic restriction aimed at preventing vertigo. Contrary to this, findings made by Wilén and de Vocht [11], Heinrich et al. [23], and Schaap et al. [13] suggest that health complaints are significantly related to the strength of the magnet, particularly on both 1.5 and 3.0 T scanners. This pointed the need to find out if exposure levels of RF magnetic fields and SMFs in hospitals within the central region of South Africa could present health and safety risks amongst staff working closer to 1.5 and 3.0 T MRI scanners.

\section{Methods}

\subsection{Study design}

Total sampling was used to measure exposure levels of RF magnetic fields and SMFs emitted by 1.5 and 3.0 T MRI scanners present in two public hospitals (hospitals $A$ and B) within Bloemfontein. A qualitative, descriptive design was adopted in this study. Measurements were collected from MR zone IV where MRI scanners are located. The emission data were measured from two 1.5 T scanners in hospital A (Signa GE medical systems) and B (MAGNETOM Aera, Siemens), and one 3.0 T scanner in hospital A (Philips). Ethical clearance was obtained from ethics committee of the Faculty of Health Sciences of the University of the Free State (reference number: UFSHSD2018/0438), and approval was obtained from the Free State Department of Health (reference number: FS201805 020).

\subsection{Measurements: SMFs and RF fields in MR zone IV}

Prior to data collection, the measurement technique was discussed with the clinical engineer who is responsible for acceptable testing and maintenance of the 3.0 T MRI scanner in hospital A. MRI chief radiographers in hospitals $A$ and $B$ also assisted in determining days when brain, cervical spine and extremities scans were performed. At the time of data collection, 2018, an average of 20 patients were scanned per day in both facilities. This included patients mostly scanned for brain and cervical spines on neurosurgery day (6-10 patients per day) and an average of three whole-body scans. Upon obtaining this information, the measurement procedure was then conducted in two rounds. Measurements for SMFs were collected in the first round and RF magnetic fields followed in the second round, with the absence of MRI personnel in zone IV.

\subsection{Static magnetic fields measurements: round one}

Spot measurements were collected using distance as an exposure surrogate. Distance points were chosen as realistic exposure pathways where MRI staff move and perform duties around the scanners and also when entering zone IV. The purpose was to obtain exposure levels at different distances across MR zone IV. A manufacturer calibrated THM1176 3-Axis hall magnetometer was used to measure the exposure levels for SMFs. The magnetometer has a range from low fields to $20 \mathrm{~T}, \mathrm{DC}$ to $1 \mathrm{kHz}$, and provide $\pm 1 \%$ accuracy. Exposure levels were measured at a 
distance of $1 \mathrm{~m}$ and $2 \mathrm{~m}$ away from the scanner, similar to a technique used by Sakurazawa et al. [24]. The magnetometer height and distance: $1 \mathrm{~m}$ and $2 \mathrm{~m}$ on the front, left and right side (Fig. 1) of the scanner were determined using a cloth measuring tape with linear-measurement markings. A THM1176 3-Axis hall magnetometer was positioned at a height of $1 \mathrm{~m}$ from the ground, with probe sensor facing the scanner magnet. The height was chosen to representative where most of the MRI activities are performed and as an approximate height chosen in a study conducted by Bonutti et al. [25] and Fatahi et al. [26].

A single THM1176 3-Axis hall magnetometer was mounted to aluminum tripod and rotated between different measurement spots once every scan was completed. Measurements were taken on an average of $30 \mathrm{~min}$ on each spot, and the hold button on magnetometer was pressed when time expired. The maximum exposure value (max. B) displayed directly from the magnetometer was noted manually on a data-recording sheet. Sixty measurements were collected at a distance of $1 \mathrm{~m}$ and 60 measurements at a distance of $2 \mathrm{~m}$ from the gantry. During measurement collection, MRI personnel was situated in the control room (zone III) scanning the patients. Scanners included in this study use passive shimming to correct static magnetic fields inhomogeneity and because of temperature sensitivity of shim materials, $B_{0}$ may shift during gradient-intensive sequences [27], resulting in each patient placed within the scanner creating a unique pattern of inhomogeneity. Based on this reasons and also to homogenize the measurement approach between SMFs and RF magnetic fields, exposure levels of static stray fields were only recorded when brain, cervical spine and extremities were scanned from 1.5 and 3.0 T scanners. Twenty spot measurements were recorded during brain scan, 20 during cervical spines and 20 when extremities were scanned. Throughout the entire measurement period, a total 720 measurements were collected from hospital A, with 360 measurements collected from each scanner. In hospital B, 360 measurements were collected from the $1.5 \mathrm{~T}$ scanner, amounting to a total of 1080 measurements collected for SMFs emissions.

\subsection{Radiofrequency magnetic fields measurements: round two}

A manufacturer calibrated TM-1963 Axis RF Field strength meter was used to measure the RF magnetic fields. The tenmars (TM)-196 can measure the RF fields ranging from $10 \mathrm{MHz}$ to $8 \mathrm{GHz}$. Prior to measurement collection, the TM-196 3 Axis RF Field strength meter was mounted on the aluminum tripod at a height of $1 \mathrm{~m}$ from the ground, with the sensor facing the MRI scanner. The exposure levels for RF magnetic fields were measured at distance of $1 \mathrm{~m}$ from the MRI scanner gantry on right and left side.

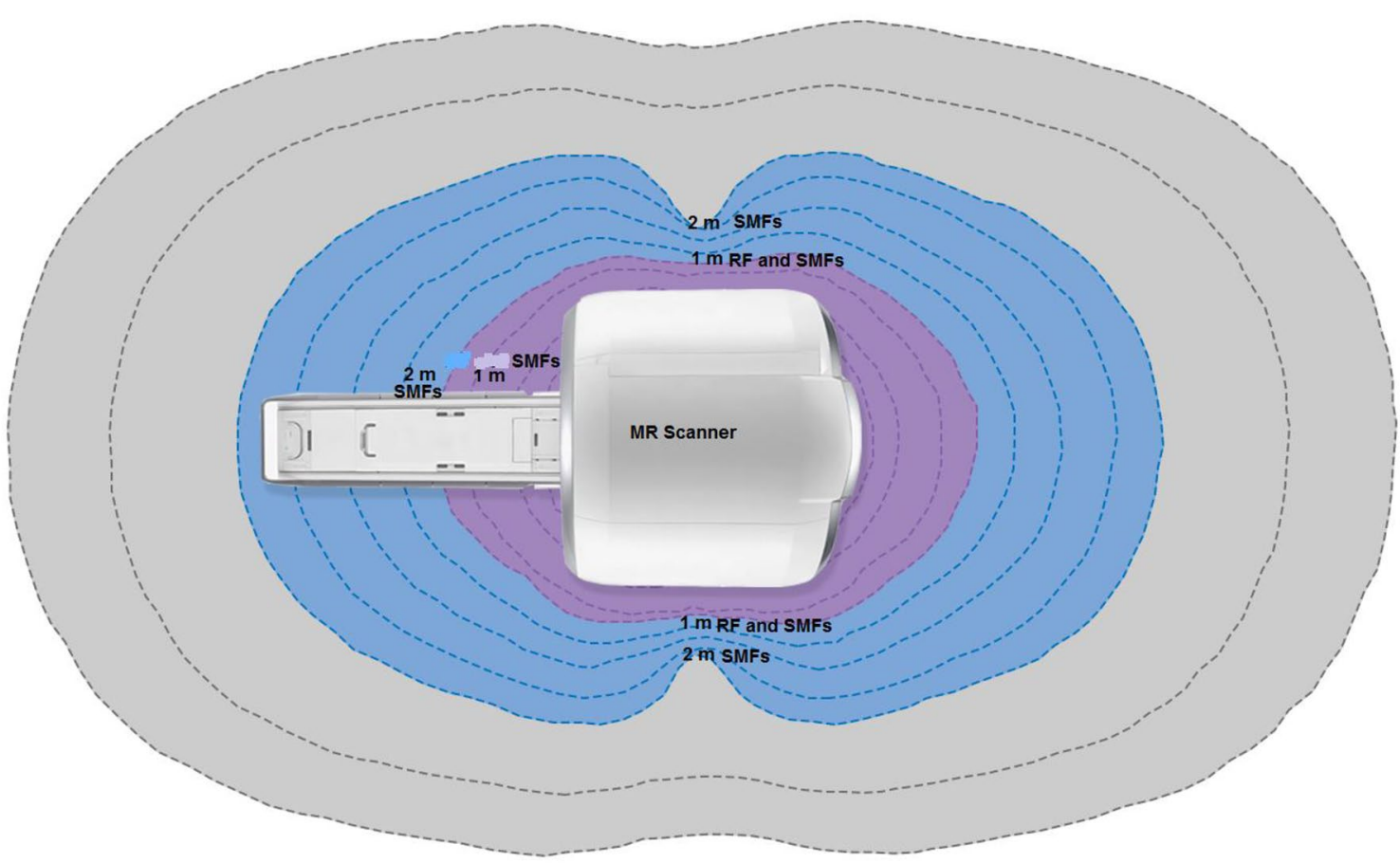

Fig. 1 SMFs and RF magnetic fields sampling positions. *SMFs spot monitoring: measurements on the left and right side were collected adjacent to the magnet housing. Front measurements were collected next to the patient table. All measurements were taken in zone IV. ${ }^{* *}$ RF magnetic fields spot monitoring: measurements were collected adjacent to the magnet housing (gantry) 
Based on the specific absorption rate (SAR) limit values for a duration of six minutes (International Electrotechnical Commission 2010), exposure levels were measured on an average of six minutes and recorded on a data-recording sheet in microTesla $(\mu \mathrm{T})$. A stopwatch timer was used to determine the recording time once the MRI personnel start to actuate the RF pulse. The measurements were collected at a distance of $1 \mathrm{~m}$ only when MRI scans were performed on patients. In each side of the scanner, 30 measurements were collected when brain scans were performed, 30 during cervical spines and 30 during extremities scans. A total of 180 measurements from each scanner, which resulted to 540 measurements, were collected for RF magnetic fields exposures from the three scanners in both hospitals.

\subsection{Calibration checks of measurement instruments}

The THM1176 3-Axis hall magnetometer and TM-196 3 Axis RF Field strength meter were within a valid calibration period of the manufacturer: which is 18 months for magnetometer and 12 months for the RF Field strength meter. The calibration status check was performed on both meters. The THM1176 3-Axis hall magnetometer probe was placed on the zero gauss chamber (ZGC) to eliminate any offset errors by zeroing the readings. The RF field strength calibration status was validated by crosschecking the meter's battery life, temperature and humidity operating conditions against operating requirements of the manufacturer.

\subsection{Data analysis}

Data were captured electronically by the researcher on SPSS version 26.0. Parametric tests were performed to test for normalities using the Shapiro-Wilk test. The independent $t$-test was performed using Levene's test of equality of variance. To compare emission levels based on scans performed, pairwise comparison tests were performed. Nonparametric tests were also performed using Friedman's test followed by Wilcoxon test, and a statistical significance level $(a)$ of 0.05 was used. Prior to performing Wilcoxon test, Bonferroni adjustment was applied at a statistical significance level $(a)$ of 0.02 to avoid type I statistical error.

\section{Results}

\subsection{Static Magnetic Fields emissions}

The strength of stray static fields was measured in selected distance spots from MRI scanners. Common scan procedures performed in both hospitals were considered when measuring stray static fields. This included evaluating if stray static fields could change during different scan procedures. Periodic maintenance of the MRI scanners included in this study is conducted every second year, followed by acceptable testing performed four times annually by maintenance engineers of respective MRI vendors. Medical physicists also conduct quality control tests weekly on the scanners included in this study. In order to evaluate compliance, exposure mean values from three scanners were benchmarked with ICNIRP [18] guidelines under occupational exposure. Exposure mean values measured at different distances from two 1.5 T scanners were compared (Table 1). Further comparisons were made when brain, cervical spine and extremities were scanned. Similar comparisons were made for the 3.0 T scanner (Table 2).

\subsection{Comparison of the 1.5 $\mathrm{T}$ scanners in hospitals $A$ and $B$}

The stray SMFs emissions were compared between hospitals A and B from two different 1.5 T MRI scanners. Parametric analysis was performed using the Shapiro-Wilk test to assess underlying differences between exposure levels recorded from the front of both scanners in 1 and $2 \mathrm{~m}$. Exposure mean values recorded for different scan procedures, i.e., brain, cervical spine and extremities, were considered, and no significant differences were observed. However, the independent sample test performed using Levene's test for equality of variance suggested a statistical significant difference for extremities at $2 \mathrm{~m}(p<0.026)$. Similar comparisons made for $1.5 \mathrm{~T}$ scanners in both hospitals for the right side suggested a statistical significant difference when exposure levels recorded for extremities at a distance of $2 \mathrm{~m}(p<0.012)$ were performed (Fig. 2b). In contrast, exposure levels recorded on the left side of both scanners in 1 and $2 \mathrm{~m}$ when brain, cervical spine and extremities were scanned shown a statistical nonsignificant difference (Fig. 2c).

A nonparametric Friedman's test was used to compare exposure mean values in all measurement positions when different scans were performed in both hospitals. At $1 \mathrm{~m}$, a statistical significant difference in hospital $A(p<0.014)$ for the left side and also hospital B for the right side $(p<0.008)$ was found. At $2 \mathrm{~m}$, both hospitals showed a statistical significant difference for the front side $(p<0.025$ and $p<0.001)$ and right side in hospital A $(p<0.020)$. Furthermore, the Wilcoxon test was performed for all measurement sides and Bonferroni adjustment was applied (0.02). At $1 \mathrm{~m}$ in hospital B, the difference was observed between cervical spine and extremities $(p<0.005)$ and in hospital A, there was a difference between cervical spine and the brain $(p<0.013)$. At $2 \mathrm{~m}$ in hospital $\mathrm{A}$, differences in the front side were observed between cervical spine and brain mean values 
Table 1 The measured values of SMFs exposure at 1 and $2 \mathrm{~m}$ from two $1.5 \mathrm{~T}$ scanners in hospitals $\mathrm{A}$ and $\mathrm{B}$

\begin{tabular}{|c|c|c|c|c|c|c|}
\hline Hospitals & $\begin{array}{l}\text { Sampling position and } \\
\text { scan performed }\end{array}$ & Mean $(\mathrm{mT})$ and SD & Minimum & Maximum & Range & Occupational exposure limits \\
\hline \multirow[t]{18}{*}{ Hospital A } & Front brain $1 \mathrm{~m}$ & $623.30 \pm 64.13$ & 504 & 684 & 180 & \multirow{36}{*}{$\begin{array}{l}<2 \mathrm{~T} \text { for the head and trunk as well as } 8 \mathrm{~T} \text { for } \\
\text { limbs }\end{array}$} \\
\hline & Right brain $1 \mathrm{~m}$ & $619.0 \pm 48.07$ & 551 & 694 & 143 & \\
\hline & Left brain $1 \mathrm{~m}$ & $602.10 \pm 43.04$ & 515 & 641 & 126 & \\
\hline & Front cervical spine $1 \mathrm{~m}$ & $644.70 \pm 40.55$ & 586 & 699 & 113 & \\
\hline & Right cervical spine $1 \mathrm{~m}$ & $653.0 \pm 34.0$ & 590 & 706 & 116 & \\
\hline & Left cervical spine $1 \mathrm{~m}$ & $657.0 \pm 39.56$ & 598 & 705 & 107 & \\
\hline & Front extremities $1 \mathrm{~m}$ & $603.20 \pm 66.16$ & 522 & 697 & 175 & \\
\hline & Right extremities $1 \mathrm{~m}$ & $582.60 \pm 56.19$ & 509 & 697 & 188 & \\
\hline & Left extremities $1 \mathrm{~m}$ & $613.70 \pm 65.39$ & 508 & 695 & 187 & \\
\hline & Front brain $2 \mathrm{~m}$ & $297.10 \pm 43.16$ & 229 & 343 & 114 & \\
\hline & Right brain $2 \mathrm{~m}$ & $312.80 \pm 34.37$ & 257 & 348 & 91 & \\
\hline & Left brain $2 \mathrm{~m}$ & $281.0 \pm 48.38$ & 227 & 349 & 122 & \\
\hline & Front cervical spine $2 \mathrm{~m}$ & $341.40 \pm 18.99$ & 311 & 370 & 59 & \\
\hline & Right cervical spine $2 \mathrm{~m}$ & $337.4 \pm 24.01$ & 300 & 368 & 68 & \\
\hline & Left cervical spine $2 \mathrm{~m}$ & $330.3 \pm 22.64$ & 302 & 368 & 66 & \\
\hline & Front extremities $2 \mathrm{~m}$ & $294.20 \pm 28.36$ & 255 & 337 & 82 & \\
\hline & Right extremities $2 \mathrm{~m}$ & $295.70 \pm 26.72$ & 251 & 331 & 80 & \\
\hline & Left extremities $2 \mathrm{~m}$ & $297.40 \pm 33.44$ & 256 & 343 & 87 & \\
\hline \multirow[t]{18}{*}{ Hospital B } & Front brain $1 \mathrm{~m}$ & $669.90 \pm 25.66$ & 631 & 709 & 78 & \\
\hline & Right brain $1 \mathrm{~m}$ & $651.40 \pm 31.53$ & 609 & 700 & 91 & \\
\hline & Left brain $1 \mathrm{~m}$ & $653.60 \pm 36.61$ & 603 & 710 & 107 & \\
\hline & Front cervical spine $1 \mathrm{~m}$ & $672.70 \pm 25.85$ & 635 & 713 & 78 & \\
\hline & Right cervical spine $1 \mathrm{~m}$ & $690.30 \pm 30.93$ & 647 & 732 & 85 & \\
\hline & Left cervical spine $1 \mathrm{~m}$ & $676.30 \pm 33.06$ & 636 & 726 & 90 & \\
\hline & Front extremities $1 \mathrm{~m}$ & $650.10 \pm 39.45$ & 601 & 709 & 108 & \\
\hline & Right extremities $1 \mathrm{~m}$ & $644.70 \pm 23.13$ & 619 & 681 & 62 & \\
\hline & Left extremities $1 \mathrm{~m}$ & $650.90 \pm 36.72$ & 610 & 708 & 98 & \\
\hline & Front brain $2 \mathrm{~m}$ & $323.0 \pm 15.73$ & 302 & 341 & 39 & \\
\hline & Right brain $2 \mathrm{~m}$ & $336.60 \pm 14.86$ & 308 & 352 & 44 & \\
\hline & Left brain $2 \mathrm{~m}$ & $330.50 \pm 12.97$ & 309 & 345 & 36 & \\
\hline & Front cervical spine $2 \mathrm{~m}$ & $349.80 \pm 8.24$ & 334 & 362 & 28 & \\
\hline & Right cervical spine $2 \mathrm{~m}$ & $342.50 \pm 8.46$ & 333 & 357 & 24 & \\
\hline & Left cervical spine $2 \mathrm{~m}$ & $343.10 \pm 8.91$ & 332 & 358 & 26 & \\
\hline & Front extremities $2 \mathrm{~m}$ & $319.0 \pm 13.10$ & 300 & 342 & 42 & \\
\hline & Right extremities $2 \mathrm{~m}$ & $327.80 \pm 24.03$ & 300 & 354 & 54 & \\
\hline & Left extremities $2 \mathrm{~m}$ & $341.40 \pm 12.33$ & 318 & 355 & 37 & \\
\hline
\end{tabular}

$(p<0.017)$ as well as extremities and cervical spine $(p<0.013)$ (Fig. 2a). Similarly, differences were observed between the cervical spine and brain $(p<0.005)$ as well as extremities and cervical spine $(p<0.005)$ in hospital B. On the right side, differences were only observed when exposure mean values for extremities were compared with cervical spine measurements $(p<0.005)$. Pairwise comparisons with Bonferroni adjustment were performed between exposure mean values recorded for the brain, cervical spine and extremities' scans at a distance of $1 \mathrm{~m}$. The difference was noted between cervical spine and extremities $(p<0.0003)$ for the right side as well as cervical spine and brain $(p<0.003)$ for the left side. There was also significant difference at $2 \mathrm{~m}$ between brain and cervical spine $(p<0.001)$ as well as cervical spine and extremities $(p<0.0001)$ for the front side. A comparison between cervical spine and extremities $(p<0.0001)$ for the right side as well as brain and cervical spine $(p<0.008)$ for the left side suggested a statistical significant difference. 


\subsection{Comparison of measurements from 3.0 T scanner}

The Shapiro-Wilk test was performed to compare exposure levels resulting from different distances, taking into account different scans performed. A statistical significant difference was noted at $2 \mathrm{~m}$, front side when brain scans were performed $(p<0.02)$. A Friedman's test comparison between the brain, cervical spine and extremities' front mean values at a distance of $1 \mathrm{~m}$ indicated a nonsignificant difference. However, a difference was observed between brain, cervical spine and extremities $(p<0.002)$ at $2 \mathrm{~m}$. Using Bonferroni adjustment, the Wilcoxon test suggested a difference between cervical spine and extremities $(p<0.013)$ at a distance of $1 \mathrm{~m}$, brain and cervical spine $(p<0.007)$ as well as cervical spine and extremities $(p<0.005)$ at $2 \mathrm{~m}$ (Fig. 3).

When comparison was made for the right side exposure levels, a statistical significant difference was shown for cervical spine at $1 \mathrm{~m}(p<0.035)$ and brain at $2 \mathrm{~m}(p<0.038)$. The difference were also noted for the extremities at $1 \mathrm{~m}$ $(p<0.013)$ for the left side exposure levels. The Friedman's test suggested a significant difference between brain, cervical spine and extremities at $1 \mathrm{~m}(p<0.001)$ and $2 \mathrm{~m}$ $(p<0.027)$ for the right side measurements. To identify where there is a difference, the Wilcoxon test with Bonferroni adjustment was performed. A significant difference was shown between cervical spine and extremities $(p<0.005)$ as well as extremities and the brain $(p<0.007)$
Fig. 2 a Comparison of SMFs exposure levels measured on the front side at 1 and $2 \mathrm{~m}$ in hospitals $\mathrm{A}$ and $\mathrm{B}$. ${ }^{*}$ Mean exposure values are displayed in Table 1; $p=$ significant difference. $\mathbf{b}$ Comparison of SMFs exposure levels measured on the right side at 1 and $2 \mathrm{~m}$ in hospitals A and B. *Mean exposure values are displayed in Table 1; $p=$ significant difference. c Comparison of SMFs exposure levels measured on the left side at 1 and $2 \mathrm{~m}$ in hospitals $A$ and $B$. * Mean exposure values are displayed in Table 1

at $1 \mathrm{~m}$. Furthermore, the difference were also observed between extremities and cervical spine $(p<0.005)$ at $2 \mathrm{~m}$. Regarding comparison between exposure mean values at the left side, Friedman's test suggested a difference between brain, cervical spine and extremities at $1 \mathrm{~m}$ $(p<0.003)$. The difference noted at $1 \mathrm{~m}$ existed between cervical spine and extremities $(p<0.005)$. At $2 \mathrm{~m}$, comparison between brain, cervical spine and extremities was significantly different $(p<0.0004)$. Cervical spine measurements were different to the brain $(p<0.005)$, and extremities were different to cervical spine measurements $(p<0.005)$.

\subsection{Radiofrequency fields emission}

The RF magnetic fields emitted by two $1.5 \mathrm{~T}$ scanners were compared to evaluated compliance with ICNIRP of 2020, reference levels for local exposures averaged over $6 \mathrm{~min}$. The incident $\mathrm{H}$-field strength of $0.36 \mathrm{~A} \mathrm{~m}^{-1}$ occupational exposure limit was converted to $0.45 \mu \mathrm{T}$. Two $1.5 \mathrm{~T}$ scanners were compared to each other to assess if there is any

Table 2 The measured values of SMFs exposure at 1 and $2 \mathrm{~m}$ from 3.0 T scanner in hospital A

\begin{tabular}{|c|c|c|c|c|c|c|}
\hline Hospitals & $\begin{array}{l}\text { Sampling position and } \\
\text { scan performed }\end{array}$ & Mean $(\mathrm{mT})$ and SD & Minimum & Maximum & Range & Occupational exposure limits \\
\hline \multirow[t]{18}{*}{ Hospital A } & Front brain $1 \mathrm{~m}$ & $1139.0 \pm 116.85$ & 977 & 1294 & 317 & \multirow{18}{*}{$\begin{array}{l}<2 \mathrm{~T} \text { for the head and trunk as well as } 8 \mathrm{~T} \text { for } \\
\text { limbs }\end{array}$} \\
\hline & Right brain $1 \mathrm{~m}$ & $1196.50 \pm 71.43$ & 1076 & 1300 & 224 & \\
\hline & Left brain $1 \mathrm{~m}$ & $1081.30 \pm 77.33$ & 995 & 1216 & 221 & \\
\hline & Front cervical spine $1 \mathrm{~m}$ & $1199.80 \pm 53.85$ & 1108 & 1282 & 174 & \\
\hline & Right cervical spine $1 \mathrm{~m}$ & $1236.40 \pm 58.43$ & 1144 & 1300 & 156 & \\
\hline & Left cervical spine $1 \mathrm{~m}$ & $1211.40 \pm 60.61$ & 1135 & 1294 & 159 & \\
\hline & Front extremities $1 \mathrm{~m}$ & $1084.10 \pm 37.72$ & 1021 & 1138 & 117 & \\
\hline & Right extremities $1 \mathrm{~m}$ & $1052.90 \pm 55.43$ & 985 & 1131 & 146 & \\
\hline & Left extremities $1 \mathrm{~m}$ & $1047.90 \pm 48.72$ & 1000 & 1133 & 133 & \\
\hline & Front brain $2 \mathrm{~m}$ & $680.0 \pm 17.84$ & 656 & 716 & 60 & \\
\hline & Right brain $2 \mathrm{~m}$ & $690.30 \pm 24.76$ & 660 & 719 & 59 & \\
\hline & Left brain $2 \mathrm{~m}$ & $680.40 \pm 17.42$ & 655 & 706 & 51 & \\
\hline & Front cervical spine $2 \mathrm{~m}$ & $712.20 \pm 2.15$ & 709 & 715 & 6 & \\
\hline & Right cervical spine $2 \mathrm{~m}$ & $710.70 \pm 0.95$ & 709 & 712 & 3 & \\
\hline & Left cervical spine $2 \mathrm{~m}$ & $712.10 \pm 1.97$ & 709 & 715 & 6 & \\
\hline & Front extremities $2 \mathrm{~m}$ & $688.30 \pm 13.43$ & 668 & 705 & 37 & \\
\hline & Right extremities $2 \mathrm{~m}$ & $685.70 \pm 12.18$ & 672 & 702 & 30 & \\
\hline & Left extremities $2 \mathrm{~m}$ & $696.60 \pm 4.40$ & 690 & 704 & 14 & \\
\hline
\end{tabular}


SN Applied Sciences (2021) 3:157 | https://doi.org/10.1007/s42452-021-04178-3

Research Article
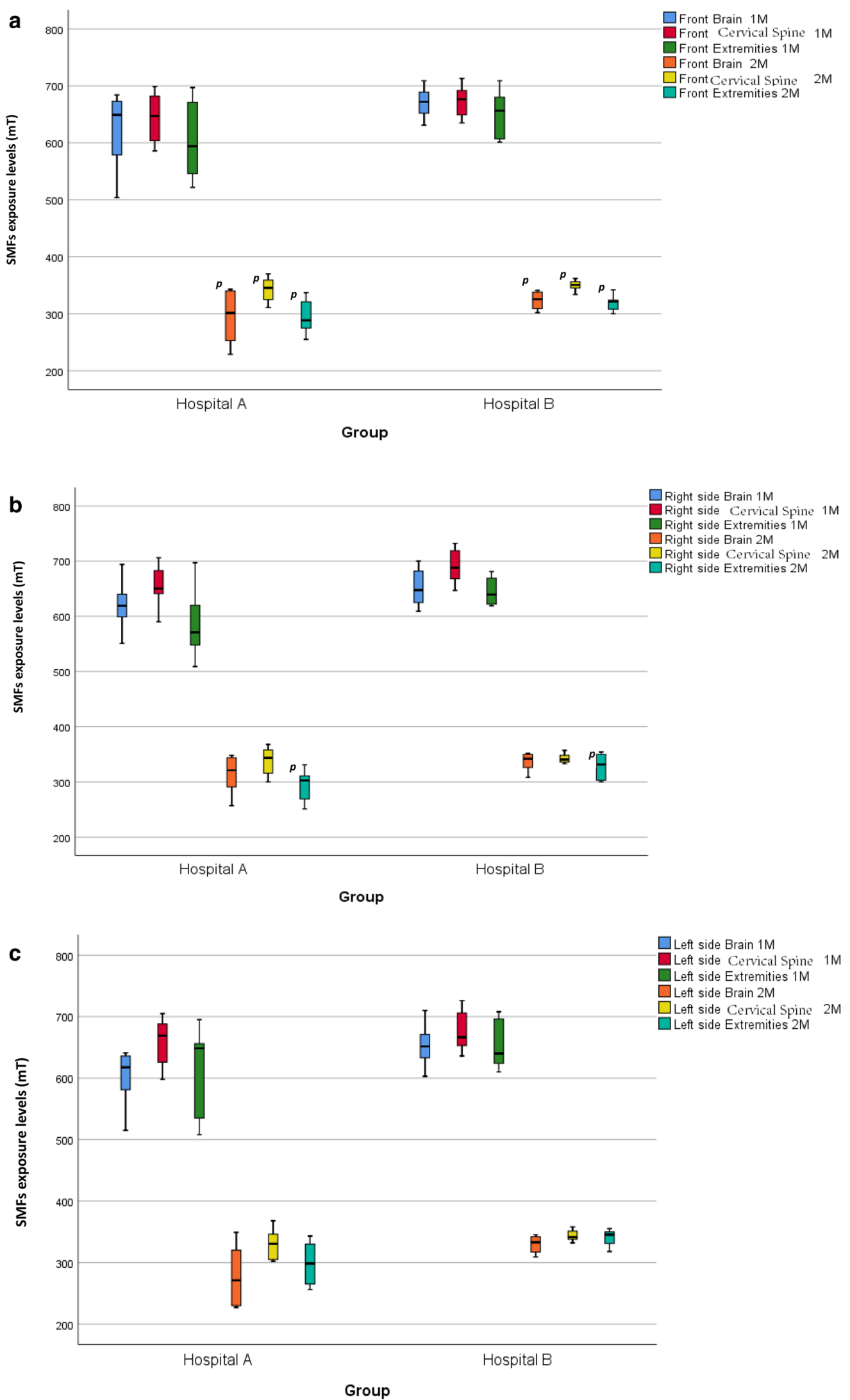

SN Applied Sciences

A SPRINGER NATURE journal 


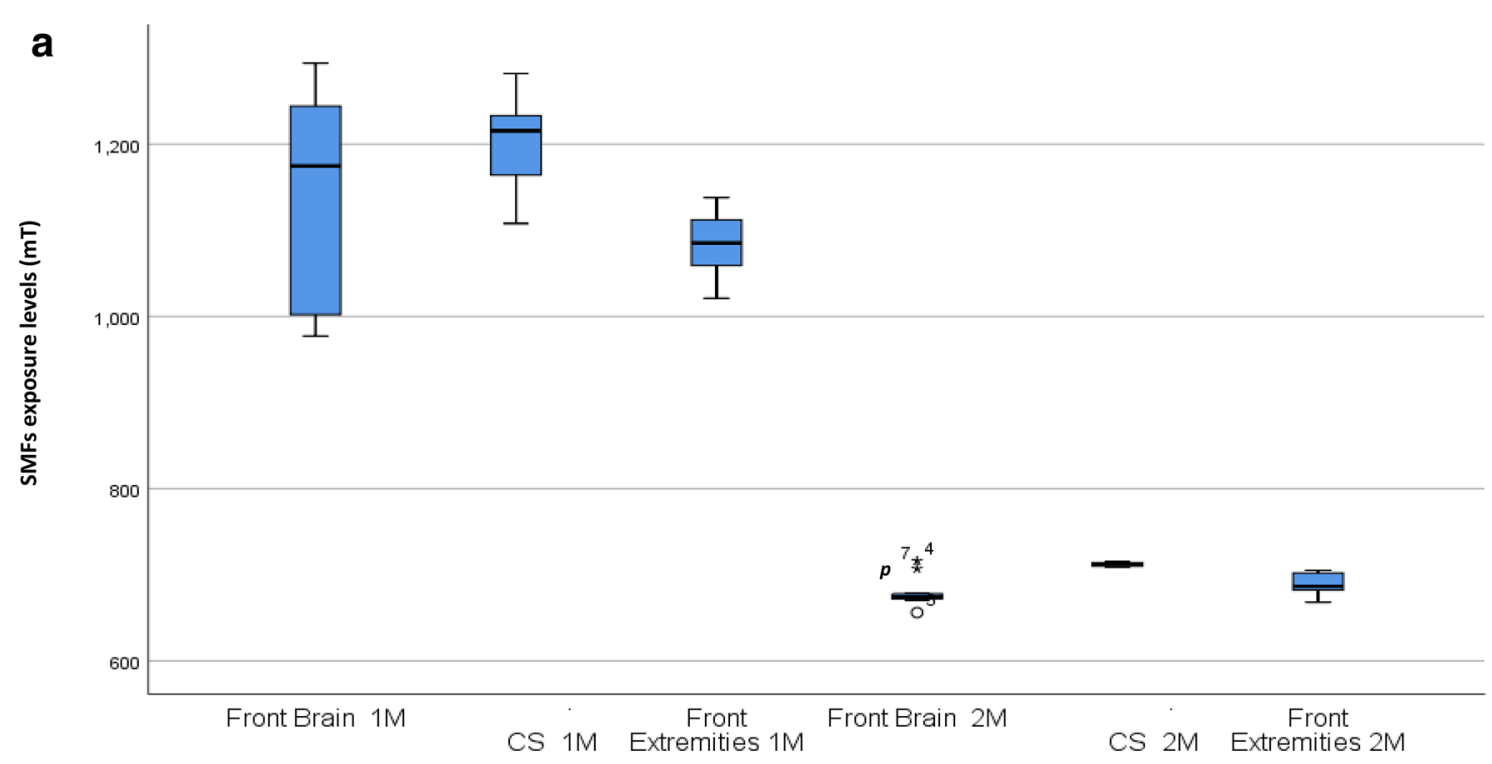

Front Side Measurements

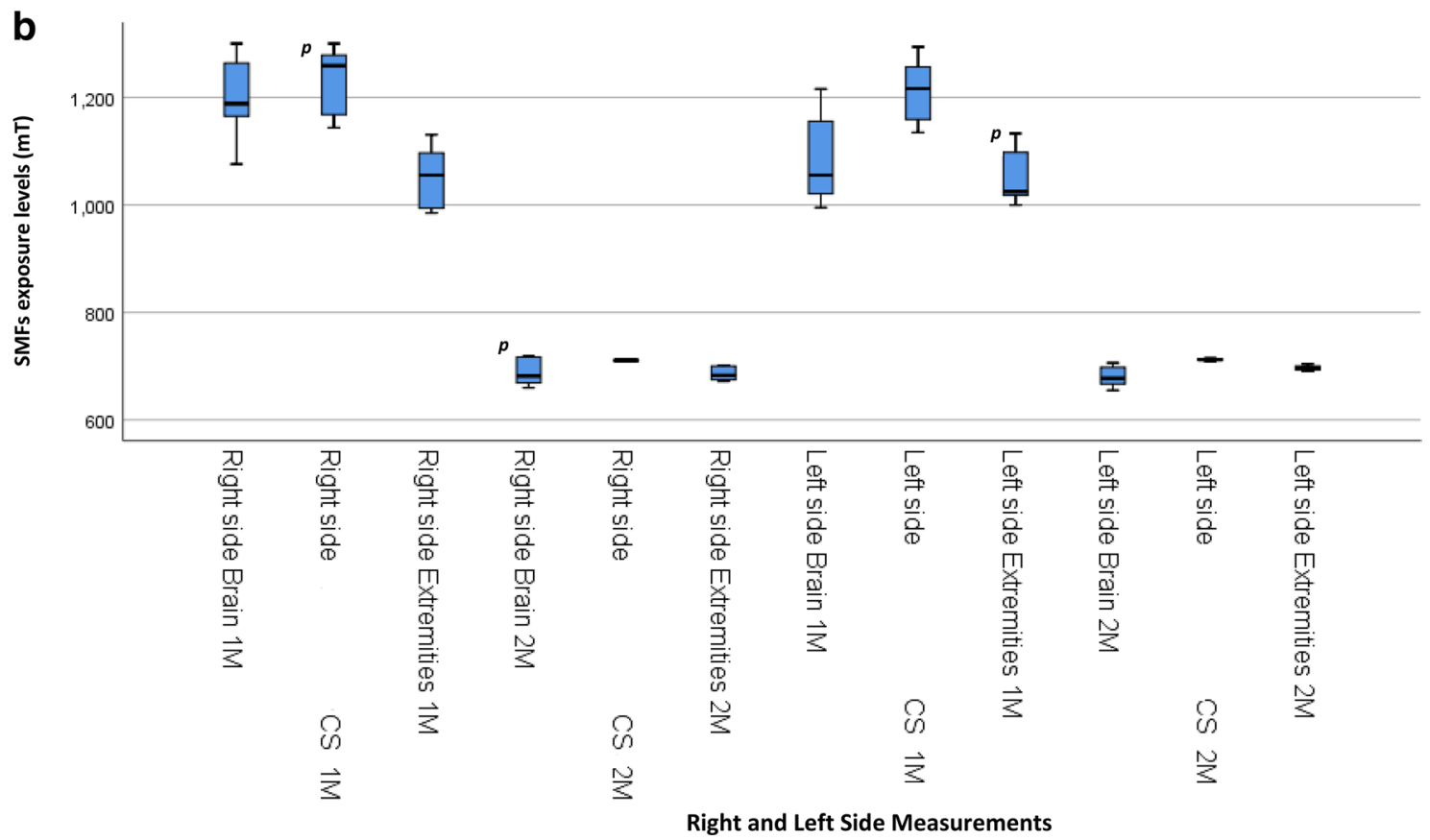

Fig. 3 a SMFs exposure levels measured on the front of 3.0 T scanner at 1 and $2 \mathrm{~m}$. ${ }^{*} \mathrm{CS}=$ cervical spine; mean exposure values are displayed in Table 2; $p=$ significant difference. $\mathbf{b}$ SMFs exposure lev-

difference with regard to $\mathrm{RF}$ magnetic fields emission on two sides of the scanners (right and left). Furthermore, RF emissions from 3.0 T scanner in hospital A were also measure to evaluate compliance. This was done by comparing exposure levels from different sides of the scanner when brain, cervical spine and extremities were scanned. Exposure levels were recorded for an average of $6 \mathrm{~min}$ at each measurement spot, when RF pulse was activated. els measured from the right and left side of 3.0 T scanner. * $\mathrm{CS}=$ cervical spine; mean exposure values are displayed in Table $1 ; p=$ significant difference

The distribution of RF magnetic field levels is presented in Fig. $4 a$ and $b$.

\subsection{Comparison between two 1.5 $\mathrm{T}$ scanners in hospitals $A$ and $B$}

Exposure levels recorded when brain, cervical spine and extremities scans were performed in both 1.5 $\mathrm{T}$ scanners 


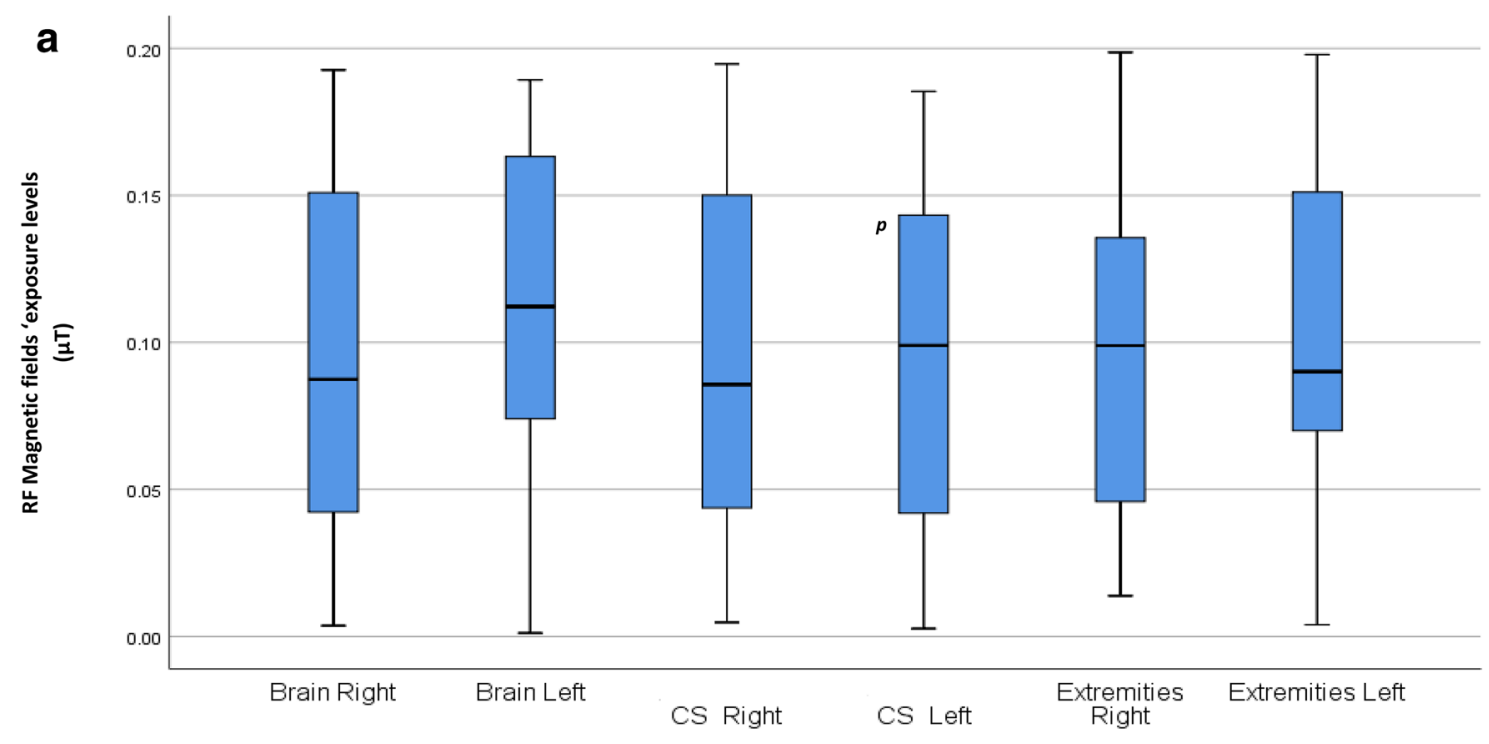

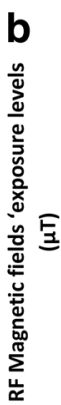

Right and Left side Measurements

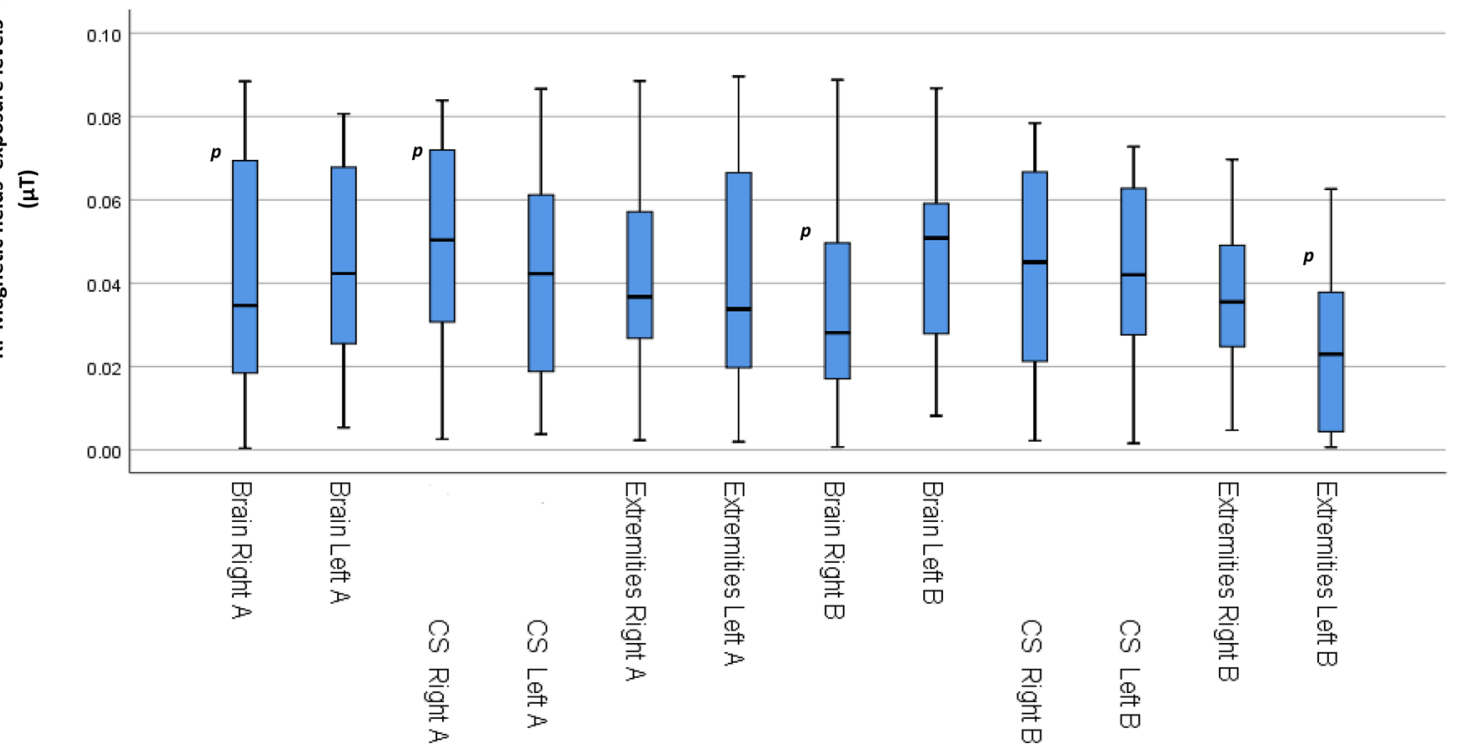

Right and Left side Measurements

Fig. 4 a Distribution of RF magnetic fields recorded at hospitals $A$ and $B$ from two 1.5 T MRI scanners. ${ }^{*} \mathrm{CS}=$ cervical spine; $A=$ hospital A-mean $0.043 \mu \mathrm{T}$ Std. 0.003; B=hospital B-mean $0.039 \mu \mathrm{T}$

were compared to one another. Similar comparisons were also made between exposure levels recorded from the left and right side at a distance of $1 \mathrm{~m}$ from the scanners. Initially, Shapiro-Wilk test was performed to check for differences between exposure levels recorded during different scan procedures. In hospital A, significant difference was shown between repeated measurements taken at the right side of the scanner when brain $(p<0.03)$ and cervical spine $(p<0.04)$ scans were performed. The differences
Std. 0.008; $p=$ significant difference. $\mathbf{b}$ Distribution of RF magnetic fields recorded from 3.0 T MRI scanner. ${ }^{*} \mathrm{CS}=$ cervical spine; hospital A-mean $0.1 \mu \mathrm{T}$ Std. 0.006; $p=$ significant difference

were also noted during brain scans $(p<0.008)$ at the right side and extremities $(p<0.02)$ at the left side in hospital B. The descriptive RF exposure values recorded in hospitals $A$ and $B$ are described in Table 3.

The Friedman's test was used to compare right side exposure levels for all scans performed in hospitals $A$ and $B$, and statistical nonsignificant difference was found. However, the difference was shown when comparing exposure levels for the left side in hospital $\mathrm{B}(p<0.001)$. When using 
Table 3 The measured RF exposure values from two 1.5 T and one 3.0 T scanners in hospitals $\mathrm{A}$ and $\mathrm{B}$

\begin{tabular}{|c|c|c|c|c|c|c|c|}
\hline Hospitals and magnetic flux & Scan performed & $\begin{array}{l}\text { Sam- } \\
\text { pling } \\
\text { position }\end{array}$ & Mean $\mu T$ and Std. & Minimum & Maximum & Range & $\begin{array}{l}\text { Reference levels for local } \\
\text { exposures averaged over } \\
6 \mathrm{~min}\end{array}$ \\
\hline \multirow[t]{6}{*}{ Hospital A 1.5 T scanner } & \multirow[t]{2}{*}{ Brain } & Right & $0.04 \pm 0.03$ & 0.0004 & 0.09 & 0.09 & \multirow{18}{*}{$\begin{array}{l}<\text { Incident H-field strength of } \\
0.36 \mathrm{~A} \mathrm{~m}^{-1} \text { limit }=0.45 \mu \mathrm{T}\end{array}$} \\
\hline & & Left & $0.05 \pm 0.02$ & 0.005 & 0.08 & 0.08 & \\
\hline & \multirow[t]{2}{*}{ Cervical spine } & Right & $0.05 \pm 0.03$ & 0.003 & 0.08 & 0.08 & \\
\hline & & Left & $0.04 \pm 0.03$ & 0.004 & 0.09 & 0.08 & \\
\hline & \multirow[t]{2}{*}{ Extremities } & Right & $0.04 \pm 0.03$ & 0.002 & 0.09 & 0.09 & \\
\hline & & Left & $0.04 \pm 0.03$ & 0.002 & 0.09 & 0.09 & \\
\hline \multirow[t]{6}{*}{ Hospital B 1.5 T scanner } & \multirow[t]{2}{*}{ Brain } & Right & $0.04 \pm 0.03$ & 0.001 & 0.09 & 0.09 & \\
\hline & & Left & $0.05 \pm 0.02$ & 0.01 & 0.09 & 0.09 & \\
\hline & \multirow[t]{2}{*}{ Cervical spine } & Right & $0.04 \pm 0.02$ & 0.002 & 0.08 & 0.08 & \\
\hline & & Left & $0.04 \pm 0.02$ & 0.002 & 0.07 & 0.07 & \\
\hline & \multirow[t]{2}{*}{ Extremities } & Right & $0.04 \pm 0.02$ & 0.005 & 0.07 & 0.07 & \\
\hline & & Left & $0.02 \pm 0.02$ & 0.001 & 0.06 & 0.06 & \\
\hline \multirow[t]{6}{*}{ Hospital A 3.0 T scanner } & \multirow[t]{2}{*}{ Brain } & Right & $0.1 \pm 0.06$ & 0.004 & 0.2 & 0.2 & \\
\hline & & Left & $0.11 \pm 0.06$ & 0.001 & 0.2 & 0.2 & \\
\hline & \multirow[t]{2}{*}{ Cervical spine } & Right & $0.1 \pm 0.06$ & 0.005 & 0.2 & 0.2 & \\
\hline & & Left & $0.1 \pm 0.06$ & 0.003 & 0.2 & 0.2 & \\
\hline & \multirow[t]{2}{*}{ Extremities } & Right & $0.1 \pm 0.06$ & 0.01 & 0.2 & 0.2 & \\
\hline & & Left & $0.1 \pm 0.05$ & 0.004 & 0.2 & 0.2 & \\
\hline
\end{tabular}

Wilcoxon test with Bonferroni adjustment, exposure levels for the extremities were different to the brain $(p<0.001)$ and also extremities to the cervical spine $(p<0.004)$. Paired samples correlation was performed to assess if exposure levels recorded from the left and right side of both scanners were correlated, and no correlation was found between the measured RF magnetic fields levels in both hospitals. Using Bonferroni adjustment, Wilcoxon test was performed to assess the difference between measurement sides in both hospitals. Exposure levels recorded from the left side during extremities' scans in hospital B were different to the ones recorded on the right side $(p<0.01)$.

\subsection{Comparison of RF magnetic field levels from 3.0 T scanner in hospital A}

The repeated measurements recorded during brain scans varied significantly for the right $(p<0.02)$ and left side $(p<0.04)$, and also for cervical spine $(p<0.05)$ on the left side of the scanner. Using a Wilcoxon's test to compare exposure levels recorded during brain, cervical spine and extremities' scans on the left and right side of the scanner, a nonsignificant difference was found. A paired samples correlation was performed to determine if exposure levels recorded on both sides of the scanner were correlated, and no correlation was found. Figure $4 \mathrm{~b}$ presents quantile distribution of RF fields during different scan procedures.

\section{Discussion}

\subsection{Static magnetic fields emissions}

The results of this study suggest that 1.5 T MRI scanners located in hospitals $A$ and $B$ had different propagation of SMFs though the nominal $B_{0}$ is the same. This finding accords results of a recent study conducted in Italy by Hartwig et al. [28]. Riches et al. [29] also indicated a significant difference between two 1.5 T scanners with a measured magnetic flux of $1540 \mathrm{mT}$ in machine $A$ and $700 \mathrm{mT}$ in machine B. Although the measured stray fields from two 1.5 T scanners were different, it is worth noting that stray static fields were also different between two distance points, $1 \mathrm{~m}$ and $2 \mathrm{~m}$ from the scanners. This has also been observed in studies that quantified stray static fields in various distances from the scanner bore [16, 30] and [31]. The significant difference was noted at a distance of $2 \mathrm{~m}$ when comparing both 1.5 T scanners. The 1.5 $\mathrm{T}$ and 3.0 $\mathrm{T}$ scanner rooms in hospital $\mathrm{A}$ are located adjacent to each, and this could be a major influence of stray static fields measured at a distance of $2 \mathrm{~m}$ from both scanners. The variation noted in the levels of stray static fields cannot be attributed to different scans performed. However, since repeated measurements were recorded on different imaging days, it can be noted that stray static fields propagate non-uniformly from scanners of the same nominal $B_{0}(1.5 \mathrm{~T}$ included in this 
study). Both scanners are manufactured by different MR vendors, and this suggests that configurations such as static magnetic field shielding, magnet type and clinical setting for installation are not similar.

Although this study used a spot monitoring, different to exposure assessment approaches used in other studies (spot measurement $\mathrm{v} / \mathrm{s}$ personal monitoring), the recorded exposure levels correspond with exposure values reported by Groebner et al. [32] Schaap et al. [14], Andreuccetti et al. [33] and Sannino et al. [34]. Since comparison between 1.5 and 3.0 T scanners would have yielded significant results, exposure levels recorded from 3.0 T scanner were compared according to distance points. A major difference in the 3.0 T scanner was also observed at $2 \mathrm{~m}$, and this could be attributed to its proximity to $1.5 \mathrm{~T}$ scanner. Though the scanner rooms are shielded, stray static fields could extend beyond the walls of zone IV into the control room [14]. The purpose of this study was to evaluate compliance for occupational exposure to SMFs in zone IV, and the recorded exposure levels comply with occupational exposure guidelines stipulated under ICNIRP [18]. Although high exposure levels were detected at $1 \mathrm{~m}$, none of them were above the exposure limit of $2 \mathrm{~T}$ for the head and trunk as well as $8 \mathrm{~T}$ for limbs.

\subsection{Radiofrequency fields emission}

Studies reporting on the RF magnetic stray fields in the MRI units are far less available, and McRobbie [35] has also noted the dearth of literature on RF magnetic fields in the MRI facilities. It has been noted in the literature that many studies are epidemiological, and they are based on a dose-response relationship between exposure and thermal effects [36-39]. In this study, the RF magnetic fields were measured at a distance of $1 \mathrm{~m}$ from two $1.5 \mathrm{~T}$ and one 3.0 T scanners. Similar RF peak value of $0.09 \mu \mathrm{T}$ was observed in both 1.5 T scanners and $0.2 \mu \mathrm{T}$ from 3.0 T scanner. Capstick et al. [40] reported a peak value of $0.08 \mu \mathrm{T}$ when RF fields' measurements from a 3.0 T scanner were recorded, and this value correlates with a peak exposure value of $0.09 \mu \mathrm{T}$ measured near a 1.5 T scanners included in this study. In addition, a mean value of $0.1 \mu \mathrm{T}$ recorded from majority scans performed in $3.0 \mathrm{~T}$ scanner accords with exposure values reported in the aforementioned study.

This results of this study show that emission of RF magnetic fields does not differ significantly between two 1.5 T scanners included in this study. The difference exist between 1.5 and 3.0 T scanners as well as different scan procedures performed. This is in agreement with the findings made by Frankel et al. [3], Frankel et al. [41] and Hansson-Mild et al. [42]. Their results suggest that RF fields vary per strength of the scanner and the variation is influenced by the RF pulse design and sequence settings-flip angle. Frankel et al. [3] also noted that scan protocols contain a number of sequences, which gives significant exposure differences between brain scans and extremities scans. Furthermore, RF magnetic fields recorded from the three scanners comply with the RF electromagnetic fields (EMF) ICNIRP guidelines [19], reference levels for local exposures.

\section{Conclusion}

The results of this study demonstrate that the three scanners from two hospitals respect ICNIRP guidelines in terms of occupational exposure to both SMFs and RF magnetic fields. However, the configurations of scanners such as clinical setting, magnetic field shielding and magnet type influence propagation of stray static fields in zone IV. The emission of RF magnetic fields is primarily influenced by factors such as scans performed, RF pulse design and sequence settings-flip angle. The limitation represented by this study was including only three MRI scanners. In the central region of South Africa, Free State, MRI services are only performed in hospitals included in this study. For this reason, this study presented exposure levels of SMFs and RF magnetic fields that MRI staff could be exposed to in zone IV while attending patients in public hospitals. Peak exposure levels exist at a distance of $1 \mathrm{~m}$ from all three scanners; this represents a distance where most MRI staff are likely to perform their tasks. However, exposure to such fields could be managed through adoption of occupational health and safety programs. Furthermore, measurement results presented in this study are likely to exemplify exposure scenarios in South African healthcare setting, since the use of 1.5 and 3.0 T scanners is common.

Data availability Not Applicable.

Code availability Not Applicable.

\section{Compliance with ethical standards}

Conflict of interest Authors declare no conflict of interest.

Consent to participate Prior to measurements collection, written informed consent was obtained from maintenance engineer who services 3.0 T scanner (Philips) and two chief radiographers from hospitals A and B. Ethical clearance was obtained from ethics committee of the Faculty of Health Sciences, University of the Free State (Reference Number: UFSHSD2018/0438).

Open Access This article is licensed under a Creative Commons Attribution 4.0 International License, which permits use, sharing, adaptation, distribution and reproduction in any medium or format, as long as you give appropriate credit to the original author(s) and the 
source, provide a link to the Creative Commons licence, and indicate if changes were made. The images or other third party material in this article are included in the article's Creative Commons licence, unless indicated otherwise in a credit line to the material. If material is not included in the article's Creative Commons licence and your intended use is not permitted by statutory regulation or exceeds the permitted use, you will need to obtain permission directly from the copyright holder. To view a copy of this licence, visit http://creativecommons .org/licenses/by/4.0/.

\section{References}

1. IARC (2002) Non-ionizing radiation, Part 1: static and extremely low-frequency (ELF) electric and magnetic fields. IARC Monogr Eval Carcinog Risks Hum 80:1-395

2. IARC (2013) Non-ionizing radiation, Part 2: radiofrequency electromagnetic fields. IARC Monogr Eval Carcinog Risks Hum 102:1-460

3. Frankel J, Wilén J, Hansson-Mild K (2018) Assessing exposures to magnetic resonance imaging's complex mixture of magnetic fields for in vivo, in vitro, and epidemiologic studies of health effects for staff and patients. Front Public Health 6:66. https:// doi.org/10.3389/fpubh.2018.00066

4. Golestanirad L, Keil B, Angelone LM, Bonmassar G, Mareyam V, Wald LL (2017) Feasibility of using linearly polarized rotating birdcage transmitters and close-fitting receive arrays in MRI to reduce SAR in the vicinity of deep brain simulation implants. Magn Reson Med 77(4):1701-1712

5. Golestanirad L, Kirsch J, Bonmassar G, Downs S, Elahi B, Martin A, lacono MI, Angelone LM, Keil B, Wald LL, Pilitsis J (2019) RFinduced heating in tissue near bilateral DBS implants during MRI at 1.5 $\mathrm{T}$ and $3 \mathrm{~T}$ : the role of surgical lead management. Neurolmage 184:566-576

6. Bongers S, Slottje P, Portengen L, Kromhout H (2016) Exposure to static magnetic fields and risk of accidents among a cohort of workers from a medical imaging device manufacturing facility. Magn Reson Med 75(5):2165-2174. https://doi.org/10.1002/ mrm. 25768

7. Huss A, Schaap K, Kromhout H (2018) A survey on abnormal uterine bleeding among radiographers with frequent MRI exposure using intrauterine contraceptive devices. Magn Reson Med 79(2):1083-1089. https://doi.org/10.1002/mrm.26707

8. Huss A, Schaap K, Kromhout H (2017) MRI-related magnetic field exposures and risk of commuting accidents-a cross-sectional survey among Dutch imaging technicians. Environ Res 156:613618. https://doi.org/10.1016/j.envres.2017.04.022

9. Rathebe PC (2018) A Narrative Review on occupational exposure to radiofrequency energy from magnetic resonance imaging: a call for enactment of legislation. Open Innovations Conference. Johannesburg. 170-175. https://doi.org/10.1109/OI.2018.85359 60.

10. Rathebe PC (2019) Occupational exposure to static magnetic fields from MRI units in health care settings: a narrative review. Ural Symposium on Biomedical Engineering, Radioelectronics and Information Technology (USBEREIT). Yekatrinburg, Russia. 9-12. 978-1-5386-8364-4/19

11. Wilén J, De Vocht F (2011) Health complaints among nurses working near MRI scanners-a descriptive pilot study. Eur J Radiol 80(2):510-513. https://doi.org/10.1016/j.ejrad .2010.09.021

12. Zanotti G, Ligabue G, Gobba F (2015) Subjective symptoms and their evolution in a small group of magnetic resonance imaging (MRI) operators recently engaged. Electromagn Biol Med 34(3):262-264. https://doi.org/10.3109/15368 378.2015 .1076442

13. Schaap K, Portengen L, Kromhout H (2016) Exposure to MRIrelated magnetic fields and vertigo in MRI workers. Occup Environ Med 73(3):161-166. https://doi.org/10.1136/oemed-2015103019

14. Schaap K, Christopher-De Vries $Y$, Slottje P, Kromhout H (2013) Inventory of MRI applications and workers exposed to MRIrelated electromagnetic fields in the Netherlands. Eur J Radiol 82(12):2279-2285

15. De Vocht F, Batistatou E, Mölter A, Kromhout H, Schaap K, van Tongeren M, Crozier S, Gowland P, Keevil S (2015) Transient health symptoms of MRI staff working with 1.5 and 3.0 Tesla scanners in the UK. Eur Radiol 25(9):2718-2726

16. Karpowicz J, Hietanen M, Gryz K (2007) Occupational risk from static magnetic fields of MRI scanners. Environmentalist 27:533-538. https://doi.org/10.1007/s10669-007-9064-1

17. Gourzoulidis G, Karabetsos E, Skamnakis N, Xrtistodoulou A, Kappas C, Theodorou K, Tsougos I, Maris TG (2015) Occupational electromagnetic fields exposure in magnetic resonance imaging systems-preliminary results for the RF harmonic content. Physica Med 31:757-762. https://doi.org/10.1016/j. ejmp.2015.03.006

18. ICNIRP (2009) Guidelines on limits of exposure to static magnetic fields. Health Phys 96(4):504-14. https://doi. org/10.1097/01.hp.0000343164.27920.4a

19. ICNIRP (2020) Guidelines for limiting exposure to electromagnetic fields ( $100 \mathrm{kHz}$ to $300 \mathrm{GHz}$ ). Health Phys 118(5):483-524

20. ICNIRP (2014) Guidelines for limiting exposure to electric fields induced by movement of the human body in a static magnetic field and by time-varying magnetic fields below $1 \mathrm{~Hz}$. Health Phys 106(3):418-25. https://doi.org/10.1097/hp.0b013e3182 9 e5580

21. Hartwig V, Romeo S, Zeni O (2018) Occupational exposure to electromagnetic fields in magnetic resonance environment: basic aspects and review of exposure assessment approaches. Med Biol Eng Comput 56(4):531-545

22. SCENIHR (2015) Potential health effects of exposure to electromagnetic fields (EMF) https://doi.org/10.2772/75635

23. Heinrich A, Szostek A, Meyer P, Nees F, Rauschenberg J, Gröbner J, Gilles M, Paslakis G, Deuschle M, Semmler W, Flor H (2013) Cognition and sensation in very high static magnetic fields: a randomized case-crossover study with different field strengths. Radiology 266(1):236-245

24. Sakurazawa H, Iwasaki A, Higashi T, Nakayama T, Kusaka Y (2003) Assessment of exposure to magnetic fields in occupational settings. J Occup Health 45:104-110

25. Bonutti F, Tecchio M, Maieron M, Trevisan D, Negro C, Calligaris $F$ (2016) Measurement of the weighted peak level for occupational exposure to gradient magnetic fields for 1.5 and 3 Tesla MRI body scanners. Radiat Prot Dosim 168(3):358-364

26. Fatahi M, Karpowicz J, Gryz K, Fattahi A, Rose G, Speck O (2017) Evaluation of exposure to (ultra) high static magnetic fields during activities around human MRI scanners. Magn Reson Mater Phys Biol Med 30(3):255-264

27. Jezzard $P$ (2006) Shim coil design, limitations and implications. In International Society of Magnetic Resonance in Medicine (ISMRM) Annual Meeting

28. Hartwig V, Biagini C, De Marchi D, Flori A, Gabellieri C, Virgili G, Ferrante Vero LF, Landini L, Vanello N, Giovannetti G (2019) The procedure for quantitative characterization and analysis of magnetic fields in magnetic resonance sites for protection of workers: a pilot study. Annal Work Expo Health 63(3):328-336 
29. Riches SF, Collins DJ, Scuffham JW, Leach MO (2007) EU Directive 2004/40: field measurements of a 1.5 T clinical MR scanner. Br J Radiol 80:483-7

30. Decat G (2007) Occupational exposure assessment of the static magnetic flux density generated by nuclear magnetic resonance spectroscopy for biochemical purposes. PIERS Online 3(4):513-516

31. Acri G, Testagrossa B, Causa F, Tripepi MG, Vermiglio G, Novario R, Pozzi L, Quadrelli G (2014) Evaluation of occupational exposure in magnetic resonance sites. Radiol Med (Torino) 119(3):208-213

32. Groebner J, Umathum R, Bock M, Krafft AJ, Semmler W, Rauschenberg J (2011) MR safety: simultaneous B-0, d Phi/ $\mathrm{dt}$, and $\mathrm{dB} / \mathrm{dt}$ measurements on MR-workers up to 7T. Magn Reson Mater Phys 24:315-322. https://doi.org/10.1007/s1033 4-011-0270-y

33. Andreuccetti D, Biagi L, Burriesci G, Cannatà V, Contessa GM, Falsaperla R, Genovese E, Lodato R, Lopresto V, Merla C, Napolitano A (2017) Occupational exposure in MR facilities due to movements in the static magnetic field. Med Phys 44(11):59885996. https://doi.org/10.1002/mp.12537

34. Sannino A, Romeo S, Scarfi MR, Massa R, d'Angelo R, Petrillo A, Cerciello V, Fusco R, Zeni O (2017) Exposure assessment and biomonitoring of workers in magnetic resonance environment: an exploratory study. Front Public Health 5:344

35. McRobbie DW (2012) Review article: occupational exposure in MRI. Br J Radiol 85:293-312. https://doi.org/10.1259/bjr/30146 162

36. Hansson-Mild K, Hand J, Hietanen M, Gowland P, Karpowicz J, Keevil S, Lagroye I, Van Rongen E, Scarfi MR, Wilén J (2012)
Exposure classification of MRI workers in epidemiological studies. Bioelectromagnetics 34(1):81-84

37. Destruel A, O'Brien K, Jin J, Liu F, Barth M, Crozier S (2019) Adaptive SAR mass-averaging framework to improve predictions of local RF heating near a hip implant for parallel transmit at $7 \mathrm{~T}$. Magn Reson Med 81(1):615-627

38. Fiedler TM, Ladd ME, Bitz AK (2018) SAR simulations and safety. Neurolmage 168:33-58

39. Hansson-Mild K, Mattsson MO (2017) Chapter 5: dose and exposure in bioelectromagnetics. In: Markov M (ed) Dosimetry in Bioelectromagnetics. CRC Press, Boca Raton, pp 101-118

40. Capstick M, McRobbie D, Hand J, Christ A, Kühn S, Hansson-Mild K, Cabot E, Li Y, Melzer A, Papadaki A, Prüssmann K, Quest R, Rea M, Ryf S, Oberle M, Kuster N (2008) An investigation into occupational exposure to electromagnetic fields for personnel working with and around medical magnetic resonance imaging equipment report VT/2007/017. European Commission, Brussels

41. Frankel J, Hansson-Mild K, Olsrud J, Wilén J (2019) EMF exposure variation among MRI sequences from pediatric examination protocols. Bioelectromagnetics 40(1):3-15

42. Hansson-Mild K, Lundström R, Wilén J (2019) Non-lonizing radiation in Swedish health care-exposure and safety aspects. Int J Environ Res Public Health 16(7):1186

Publisher's Note Springer Nature remains neutral with regard to jurisdictional claims in published maps and institutional affiliations. 